Slavica

bruxellensia

\section{Slavica bruxellensia}

Revue polyphonique de littérature, culture et histoire

slaves

$6 \mid 2010$

Linguistique russe

\title{
Paul Garde, Les Balkans, héritages et évolutions
}

\section{Anaïs Krawczykowska}

\section{OpenEdition \\ Journals}

Édition électronique

URL : http://journals.openedition.org/slavica/357

ISSN : 2034-6395

Éditeur

Université libre de Bruxelles - ULB

Édition imprimée

Pagination : 66-67

ISSN : 2031-7654

Référence électronique

Anaïs Krawczykowska, "Paul Garde, Les Balkans, héritages et évolutions », Slavica bruxellensia [En ligne], 6| 2010, mis en ligne le 15 juin 2010, consulté le 21 septembre 2020. URL : http://

journals.openedition.org/slavica/357

Ce document a été généré automatiquement le 21 septembre 2020.

\section{c) $(1) \Theta$}

Les contenus de Slavica bruxellensia sont mis à disposition selon les termes de la Licence Creative Commons Attribution - Pas d'Utilisation Commerciale - Pas de Modification 3.0 France. 


\title{
Paul Garde, Les Balkans, héritages et évolutions
}

\author{
Anaïs Krawczykowska
}

\section{RÉFÉRENCE}

Paul Garde, Les Balkans, héritages et évolutions, Paris,Flammarion, coll. « Champs actuel », $217 \mathrm{p}$. 
1 Les Balkans, ce territoire montagneux (balkan signifiant "Montagne » en turc) aussi appelé "Europe du sud», est plus que jamais au cœur de l'actualité. Or il semblerait que la géographie soit un paramètre bien insuffisant à sa définition. Menaçante pour les uns, prometteuse pour les autres, l'ex-Yougoslavie laisse apparaître de nombreux enjeux stratégiques, aussi bien politiques qu'économiques ou encore historiques. Ces dernières années ont remis les pays des Balkans sur le devant de la scène, et pas toujours pour de très bonnes raisons : éclatement de la Yougoslavie, massacres en Bosnie-Herzégovine, témoin d'une barbarie incroyable, mouvement indépendantiste au Kosovo... Cette région, « la poudrière de l'Europe » comme on la surnomme au $\mathrm{XX}^{\mathrm{e}}$ siècle, n'a décidément pas fini de faire parler d'elle.

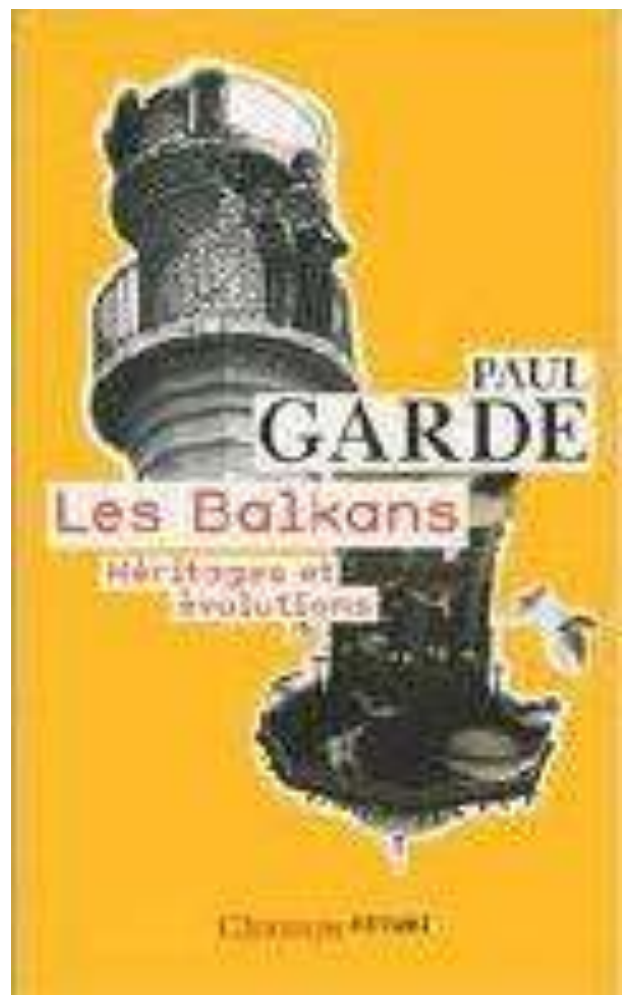

2 Paul Garde, professeur émérite à

l'université de Provence, auteur de nombreux ouvrages de référence sur les Balkans et le monde slave, nous fait découvrir dans ce livre une terre de contrastes, adorée et haïe, pauvre et riche, magnifique et maudite.

3 L'ouvrage s'organise en deux parties, chacune divisées en cinq chapitres. Cette façon très didactique et pratique de présenter les Balkans a pour avantage de permettre au lecteur de s'y retrouver facilement. Une première partie intitulée «Espace et temps balkaniques » donne l'occasion au lecteur de faire le point sur ses connaissances et de rompre avec certains préjugés. Le premier chapitre, à l'aide d'indispensables cartes, dresse les limites géographiques des Balkans. Le chapitre suivant, dédié à ses habitants, s'avère quant à lui très utile dans la compréhension des trois autres chapitres consacrés à l'histoire de la région, depuis l'antiquité jusqu'à nos jours. Ce récapitulatif historique dresse le portrait d'une terre asservie tour à tour par les Ottomans, par les Austrohongrois puis par les communistes, ravagée par des guerres, déchirée par des dirigeants peu scrupuleux. L'auteur évite les clichés et n'a pas peur des mots ni des chiffres. À titre d'exemple, un passage très marquant pour le lecteur est focalisé sur la guerre de Bosnie (1992-1995) où le nettoyage ethnique, les exactions à l'encontre de la population et les déplacements massifs des non Serbes firent 100000 morts et entre 2 et 3 millions de déplacés. Mais le passé des Balkans est aussi tumultueux que son avenir est incertain. L'indépendance du Kosovo en février 2008 a ravivé les passions s'étaient-elle jamais éteintes?

4 La seconde partie de l'ouvrage, «spécificités balkaniques » se focalise sur l'identité balkanique et les clivages de cette zone instable et mouvementée. Comment imaginer une possible intégration de certains pays de l'ex-Yougoslavie dans un tel contexte? L'auteur examine les causes des conflits, datant de l'époque des invasions ottomanes, déjà responsables de déplacements massifs de population, et concourants aux fractures 
religieuses (principalement du fait de l'islamisation des Albanais et des Bosniaques) et à la haine cultivée entre les différents peuples balkaniques. Mais si ces derniers ne partagent pas tous la même langue, les mêmes traditions ni la même religion, ils ont en commun un amour pour leur patrie respective à toute épreuve. Cette « obsession de la nation » dont fait état l'auteur fait l'objet d'un chapitre qui fournit diverses définitions du terme très polémique de "nation ». Les autres chapitres tentent quant à eux de définir les Balkans sur la scène européenne et même mondiale, ouvrant de nouvelles perspectives pour cette terre trop longtemps reléguée au statut de zone de seconde classe.

5 Ce voyage à travers le temps et l'espace laisse forcément de nombreuses questions en suspens. Le lecteur s'interroge et souhaiterait en savoir plus, mais la bibliographie, bien étoffée donne quelques pistes. À noter que les termes relevant d'un vocabulaire spécialisé sont repris à la fin de l'ouvrage, dans un lexique précis et salutaire pour le lecteur profane. Le fait que l'ouvrage ne requiert aucun pré-requis et la simplicité du langage de l'auteur, néanmoins concis, facilite grandement la lecture et la rend agréable.

Entre précis historique-géographique et politique, cet ouvrage s'adresse définitivement à tous, aussi bien à l'étudiant qu'au simple curieux, passionné d'Histoire, avide d'en savoir plus sur une terre voisine, beaucoup plus proche de nous qu'il n'y parait et sur le chemin de l'Union Européenne.

INDEX

Mots-clés : histoire des Balkans

Index géographique : Balkans, Bosnie, Bulgarie, Croatie, Kosovo, Macédoine, Monténégro, Serbie, Slovénie, Yougoslavie

\section{AUTEURS}

\section{ANAÏS KRAWCZYKOWSKA}

Étudiante à l'Université Libre de Bruxelles en Langues et Littératures slaves 